10.21611/qirt.2016.163

\title{
Thermography in the stroke rehabilitation
}

by ${ }^{*}$ Béla Hegedűs M.D., ${ }^{* *}$ Szilvia Hegedűs and ${ }^{* * *}$ Márta Gálfi Ph. D

\author{
*Ss. Cosma and Damian Rehabilitation Hospital, Visegrád, Hungary, arthrodent@freemail.hu \\ ${ }^{* *}$ Graduate School of Educational Sciences, University of Szeged, Hungary, \\ hege.szilus@gmail.com
}

***Faculty of Juhász Gyula Education, Department of Environmental Biology, University of Szeged, Hungary, galfi@jgypk.u-szeged.hu

\section{Introduction}

Physiotherapy records offer a good opportunity to monitor the efficacy of stroke rehabilitation. We also know that good muscle pump function is necessary to maintain normal biological circulation in the limbs. In the case of stroke, numerous symptoms indicate changes in venous circulation.

\section{Objective}

The aim of the study is to measure changes to both articular functions and microcirculation in the limbs and to investigate the link between them.

\section{Patients and Methods}

Rehabilitation was initiated $13 \pm 4$ days following the acute phase in 16 randomly selected ischaemic stroke patients with upper limb-dominant hemiparesis. Thermographic images were taken of the limbs pre- and posttreatment with a Fluke Ti20 thermal imager, and percentage change in articular function was measured. We administered physiotherapy (continuous passive motion, guided active exercise, increased articular motion, muscle strengthening exercises and walking retraining (30 $\mathrm{min})$ ), massage (brush and connective tissue massage (30 $\mathrm{min})$ ) and descending galvanic treatment (bipolar (10 min)) 15 times each. The side not presenting neurological symptoms was used as a control.

\section{Results}

Compared to the pretreatment condition, articular function showed significant improvement on the affected side due to treatment (upper limb: pretreatment: 68.32\%; posttreatment: 92.4\%; lower limb: pretreatment: $72.16 \%$; posttreatment: $94.42 \%)(p<0.05)$. Thermography confirmed microcirculatory disruption in the limbs on the affected side compared to the control side in $100 \%$ of the cases examined. Thermographic testing found a temperature increase of half a degree or more due to treatment on the affected side compared to the pretreatment condition (upper limb: pretreatment: $31.54^{\circ} \mathrm{C}$; posttreatment: $32.61^{\circ} \mathrm{C}$; control side: $33.09^{\circ} \mathrm{C}$; lower limb: pretreatment: $30.52^{\circ} \mathrm{C}$; posttreatment: $31.61^{\circ} \mathrm{C}$; control side: $\left.31.75^{\circ} \mathrm{C}\right)\left(p \geq 0.5^{\circ} \mathrm{C}\right)$. A close correlation $(r)$ was demonstrated between articular functions and changes in temperature (shoulder: 0.634; elbow: 0.572; wrist: 0.530; hip: 0.630: knee: 0.532; ankle: 0.544$)(p<0.05)$.

\section{Conclusion}

Our results suggest that thermography represents an appropriate method for monitoring the effects of stroke rehabilitation. Even in the acute phase, it may also be possible to draw conclusions from thermographic testing about the course of the injury and the potential efficacy of treatment.

This research was supported by the European Union and the State of Hungary, co-financed by the European Social Fund in the framework of TÁMOP 4.2.4.A/2-11-1-2012-0001 'National Excellence Program' and by TÁMOP-4.1.1.C-12/1/KONV-2012-0012. 